\title{
Accreditation of Pharmacy Institutions: Design of Curriculum
}

\author{
Satish B Bhise* and Adwait M Deshpande
}

Sinhgad Institute of Pharmaceutical Sciences, S.No.309/310, Off Mumbai-Pune Expressway, Kusgaon (Bk.), Lonavala-410401 Pune (MS) INDIA

\begin{abstract}
Background of accreditation and evaluation criteria have been discussed in the earlier two articles of this series. Design of the curriculum and its implementation is the core issue related to accreditation. Current article highlights how curriculum should be designed to meet the changing needs of the society. Linkage between Program Educational objectives (PEOs), Program Outcomes (POs) and Course Objectives (COs) is emphasized. Illustrative list of PEOs, POs and COs for B. Pharm. course has been presented. Division of courses into three areas 'Must know', 'Useful to know' and 'Desirable to know' has been suggested. Illustrative list of topics in these areas has also been given.
\end{abstract}

Keywords: Accreditation, Curriculum Design, Autonomy, Pharmacy Institutions.

\section{INTRODUCTION}

Accreditation is a pre-requisite for autonomy for the institution. During autonomy, the institution is supposed to design and implement its own courses. Thus, the purpose of accreditation of professional courses is to find out if institutions seeking accreditation design and implement their educational programs in a professional manner or not. By "professional manner", we mean planning and implementation of "Key" parameters like Mission, Vision, PEOs, POs, and COs in a logical sequence. ${ }^{1}$ It is expected that performance in key parameters should be in a dynamic manner, relevant to changing needs of the society around them. If "key" parameters are to be constantly modified, then the reflection of attitude is to be presented in the "Curriculum". Thus, a dynamic curriculum relevant to the changing needs of the society is one of the central factors in Accreditation. Hence much emphasis has been placed on design of the curriculum in the present article. Unfortu- nately in the conventional model of a large number of affiliated colleges linked to a public-financed University, design of curriculum for a large number of colleges may not be done so seriously so that the changing needs of the society are reflected in the curriculum.

PEOs: While writing Programme Education Objectives (PEOs), it should be ensured that content of the PEOs reflect actual field needs of the profession. After identifying professional needs, tasks underlying every objective need to be specified. For performing identified task, a set of Attitude, Knowledge and Skills (A-S-K) should be defined either individually or collectively. ${ }^{2}$ Based on these activities, a curriculum should be designed. A designed curriculum is implemented further by the system of education. It involves pedagogy of education. It is expected that all events included in identification of PEOs and implementation of curriculum is one aspect of system.
Submission Date : 21-08-14 Accepted Date : 03-09-14

DOI: $10.5530 / \mathrm{ijper} .48 .4 .1$

Address for correspondence: Dr S B Bhise Sinhgad Institute of Pharmaceutical Sciences, S.No.309/310, Off MumbaiPune Expressway, Kusgaon (Bk.), Lonavala-410401

Pune (MS) India

E-mail: satishbhise@gmail. com

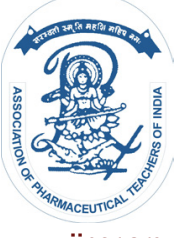

www.ijper.org 
On the other hand, Programme Outcomes (POs), and Course Outcomes (COs) constitute another aspect of the system. ${ }^{3}$ They are based on content of the curriculum, and its actual implementation which is based on the field situation. It is interesting to find out whether POs and COs are really capable of achieving PEOs or do they need any corrections. If it is observed that POs and COs are missing in attaining certain PEOs, then appropriate changes should be made in the curriculum so that PEOs on one hand and POs as well as COs on the other hand are perfectly consistent. It is assumed that, COs being part of POs, are consistent with each other. If they are not consistent, then minor changes in COs to get them aligned with identified POs will serve the purpose. The development of POs and COs in consonance with PEOs is the 'process of development of a curriculum'.

Needs of the society are not static. Based on changing needs of the population and constant technological development, every profession evolves with time. The best example is of computers which has transformed probably every profession in leaps and bounds. The changing needs of society should be reflected in modified PEOs. Based on the modified PEOs, POs and COs should be modified in a consistent manner. Fortunately for a profession like pharmacy, changing societal needs is reflected in modified regulations both at national and global level. Based on the regulatory changes, PEOs, POs and COs can be modified.

There are three constant drives, which change the spectrum related to drugs,

1. New diseases are emerging e.g. AIDS, Swine flu etc.

2. New drugs for existing diseases are being developed e.g. new H2 blocker, new dopamine receptor blockers etc.

3. More and more drugs are coming out of patent life and are getting converted to generic drugs.

Since cost of research related to point no. 1 and 2 are on higher side, most of Indian pharmaceutical companies are working in the area of development of generic drugs. WHO concept of essential drugs states that, a limited number of drugs are adequate for controlling diseases of majority population. Such limited number of drugs has been labeled as "Essential Drugs". Since majority of Indian pharmaceutical companies are operating on generic drugs, and majority of Indian population needs affordable drugs, the concept of essential drugs is very vital for India. Thus if entire pharmacy curriculum is designed in such a way that essential drugs form centrality of the curriculum, then the curriculum will turn out to be very relevant to the Indian conditions.
Thus PEOs, POs and COs should revolve around essential drug list as identified by our health professionals. It has to be ensured that PEOs, POs \& COs are sequentially linked to each other. If there is any discord between these three components, then appropriate changes in the content of any one of them are desirable. Usually PEOs being gross objectives, they are unlikely to change unless there is any major shift in the emphasis of the profession. It is rare to happen, however it is possible. A minor change in PEOs may be reflected in change in POs. Along-with change in POs modifications in content of COs is possible. Not only that, new courses may have to be added in order to reflect technological modifications in the content of profession as well as curriculum e.g. courses on nanotechnology, bioinformatics, human genome, personalized medicine were not necessary few decades back; however these courses can be linked to new job creations. Such courses along-with relevant objectives need to be added with changing technological needs

\section{Illustrative PEOs for a B. Pharm. Course can be as follows:}

- To know physical, chemical and biological properties of drugs.

- To know formulation-related factors of dosage forms.

- To know formulation and evaluation processes.

- To know clinical uses of drugs.

- To know Pathophysiology, Microbiology and Biochemistry related to disease state.

- To know Indian and Global regulations about manufacture and use of drugs.

- To know Quality control and Quality assurance of drugs.

- To know wholesale and retail distribution of drugs.

- To know about stability and storage of drugs.

- To know manufacturing and clinical uses of drugs derived from biotechnology origin.

\section{Illustrative POs for a B.Pharm Course can be as fol- lows:}

At the end of getting B.Pharm degree every student should be able to:

- Manufacture any pharmaceutical formulation of drugs by following Good Manufacturing Practices (GMP)

- Evaluate any pharmaceutical formulation following Good Laboratory practices (GLP) 
- Store drugs in a stable form.

- Follow practice of all necessary regulations related to manufacture and use of drugs.

- Record action and clinical uses of drugs.

- Record all possible adverse reactions to clinical uses of drugs

- Know and remedy physicochemical interactions amongst drugs and their consequences.

- Record all clinical interactions amongst drugs or with food.

- Participate in clinical trials for clinical records and monitoring of trials.

- Participate in wholesale and retail distribution of drugs in effective manner.

In order to attain PEOs and POs, courses need to be designed and for every course, course objectives (COs) need to be identified. Illustrative list of courses and representative COs for one course are listed herewith.

\section{LIST of COURSES}

- Physical Pharmacy

- Pharmaceutics

- Pharmaceutical Analysis

- Pharmacology

- Pharamcovigilance

- Impurity Profile of drugs

- Biopharmaceutics

- Pharmaceutical Jurisprudence(Indian)

- WHO Good Manufacturing Practices

- Good Laboratory Practices

- Global regulations for drugs

- Clinical Trials

- Clinical Biochemistry

- Clinical Microbiology

- Essential Drugs

- Social Pharmacy

- Indigenous Drugs (Complimentary \& Allied Systems)

- Properties of Drugs

- Distribution of Drugs

- Stability of Drugs

- Quality Control \& Quality Assurance of Drugs

- Human Anatomy \& Physiology

- Clinical Immunology
For every enlisted course, objectives need to be defined. Objectives for one of the course i.e. WHO GMP are given below as an illustration.

\section{Representative Course Objectives for a course on GMP:}

- Introduction to WHO GMP

- To understand Quality Management

- To understand sanitation and Hygiene

- To understand Validation

- To handle Complaints and recalls

- To know Contract production and Analysis of Drugs

- To understand self Inspection

- To understand Personnel

- To understand Premises

- To know equipments used for Manufacture of drugs

- To understand Materials used for Manufacture of drugs.

- To Comprehend Documentation related to Manufacture of drugs.

- To Know Manufacture of Sterile Drugs

- To Comprehend about Active Pharmaceutical Ingredients (APIs)

Similar course objectives for every course need to be identified \& validated based on opinion of the experts and then consolidated for the purpose of implementation.

Once the course objectives are identified and consolidated by extensive comments from various experts, then detailing of the course content, preparation of learning material, availability of right literature for support, development of evaluation criteria for assessment, development of Question bank, Power-Point presentations can be prepared by the concerned teaching staff in association with experts from Pharmaceutical industries.

Writing PEOs, POs, and COs is only one part of the curriculum. There is much gap between a cup and a lip. All what is identified as a curriculum may find practical issues when it starts getting implemented. Things which have been identified may change with time; the change may be reflected in regulations; it may be reflected in documentation; new supporting literature may be available; trainer's comprehension about the topic may be different.

Usually a professional curriculum consists of three major components; 'what students must know', 'what 
is useful to know' and 'what is desirable to know'. If contents of these three components are carefully defined, then, the curriculum becomes more precise and effective. Involvement of professionals working on the field during design of the curriculum is very important; because, they are very clear about "basic minimum activities need to be performed by students in order to become effective professionals". This constitutes base of the pyramid of the curriculum. Second and third stage of the pyramid is to add useful to know and desirable to know based on actual needs of the field. Academicians involved in the process of curriculum making should appreciate these facts thoroughly and should consult professionals on the field from time to time so that curriculum satisfies changing needs of society

"Must know" are the areas which every student must understand. These are basic contents of the profession. The second is useful to know. Depending on interest and actual filed needs, a fraction of students may know these areas fully or partially. Third is desirable to know areas. It indicates the optional areas where a section of students with special needs may desire to know. These may be newer additions in the profession.

Following topics are illustrative only. Few additional topics may be added or deleted depending on the actual training needs

\section{MUST KNOW AREAS}

Basic science relevant to physical, chemical and biological properties of drugs. Clinical uses of drugs, Pharmacovigilance, Stability and storage of drugs, Functional Human anatomy \& Physiology, Biochemistry and Microbiology as related to mechanism of action of drugs. WHO concept of essential drugs. Indian laws related to manufacture, distribution and uses of drugs with emphasis on cGMP, Vaccines, Sera; Patents about drugs and dosage forms.

\section{USEFUL TO KNOW AREAS}

Marketing of drugs, Global regulations of drugs, Synthesis of drugs, Analysis of drugs, Botany of medicinal plants, Standardization of Indigenous drugs.

\section{DESIRABLE TO KNOW AREAS}

Social Pharmacy, Biosimilars, Monoclonal antibodies, Global drug market, International Conference on Harmonization (ICH), Professional associations related to Pharmacy, Complimentary and Allied Systems of Medicine (CAM) as identified by WHO, Global regulations about CAM, Export documentation related to drugs.
Shifting of a topic from one area to another may be done with changing emphasis related to the profession on the field.

The courses listed under 'must know area' are the core courses. They should contain 65 to $70 \%$ of the curriculum. Useful to know and Desirable to know together are expected to contain about $30 \%$ of the curriculum.

Live interaction with industry is one way of keeping the courses updated. Industry cannot survive unless new products and new technologies are incorporated in its day-to-day functioning. Such rapid changes are necessary for surviving in the highly competitive world. In addition, global regulatory changes followed by reflection in local regulatory requirements are one of the prime drivers of industrial change. If academic institutions keep updated along-with changes in the industrial scenario, it has to be reflected in the curricular changes. It has been pointed out that $5-10 \%$ curricular change every year is an eventual possibility. In order to meet such changes, existing faculty of academic institutions have to keep pace with rapid industrial changes and modify the curriculum accordingly.

Gaps in the knowledge with respect to changing regulatory and industrial changes need to be identified and offered in the form of short term continuing education courses. Content beyond syllabus is a common requirement for all time to come. Annual proceedings of professional bodies like Indian Pharmaceutical Association (IPA), Indian Pharmacological Society (IPS), Indian Drug Manufacturers' Association (IDMA), Organization of Pharmaceutical Producers of India (OPPI), Indian Chemical Manufacturers' Association (ICMA), Pharmaceutical \& Allied Manufacturers' \& Distributors' Association Limited (PAMDAL) provides indication of challenges faced by the partners in that year. It is necessary that a periodic review of proceedings of professional bodies should be first given to faculty and then to students at least once in few years.

Experts from various areas who have field experience should participate in training of students so that actual needs of the profession "as they need are sensitized by the students. Filling up gaps in knowledge is a constant ongoing activity to match Pos \& COs with PEOs on continual basis.

\section{ACKNOWLEDGEMENT}

Nil

\section{CONFLICT OF INTEREST}

Nil 


\section{REFERENCES}

1. Bhise S.B. Accreditation of Pharmacy Institutions: Background and the newnorms. IJPER. 2013; 47(2): 188-92.
2. Bhise S.B, Deshpande A.M. Accreditation of Pharmacy Institutions: Evaluation Criteria. IJPER. 2014; 48(1): 1-5.

3. National Board of Accreditation (NBA). Accreditation manual for Pharmacy UG programmes. New Delhi: NBA; 2013. 